\title{
O constante desafio de decifrar a esfinge capitalista
}

The constant challenge of deciphering the capitalist sphinx: an interview with Edmundo Fernandes Dias

\author{
Entrevista com o Professor Dr. Edmundo Fernandes Dias* \\ por Monica de Jesus Cesar
}

Em junho de 2003, durante uma entrevista à Revista Universidade e Sociedade (ano XIII, n. 30), especialmente, para a sessão "Memória do Movimento Docente", o Professor Edmundo Fernandes Dias proferiu a célebre frase "fazer política como quem ensina e ensinar como quem faz política". Como a sua história se confunde com a criação e consolidação do Sindicato Nacional dos Docentes das Instituições de Ensino Superior (ANDES-SN), pautado numa luta sindical autônoma, combativa e classista, a frase retrata a conjunção da sua intelectualidade e militância política. Cabe destacar, inclusive, a importância dessa entidade no momento atual em que os(as) docentes das Instituições Federais de Ensino Superior (IFES) fazem uma de suas maiores greves, alcançando a quase totalidade das universidades e institutos federais do país. Professor aposentado do Instituto de Filosofia e Ciências Humanas (IFCH) da Universidade Estadual de Campinas (UNICAMP), Edmundo concluiu a graduação pela Universidade Federal Fluminense (UFF), em 1967, e depois foi para o Chile, onde permaneceu por um ano na Facultad Latinoamericana de Ciencias Sociales (FLACSO). Ao retornar ao Brasil, em 1969, ele lecionou, simultaneamente, na Universidade Federal Fluminense (UFF) e na Pontifícia Universidade Católica do Rio de Janeiro (PUC-Rio) - de onde foi demitido em 1974, quando o setor da direita passou a comandar o Departamento de Sociologia da Universidade. Antes de ingressar na UNICAMP, em 1976, ele teve uma breve passagem pela

Universidade do Estado do Rio de Janeiro (UERJ), ainda denominada Universidade do Estado da Guanabara (UEG), assessorando um projeto de Medicina Social. Doutor em História Social, Edmundo realizou profunda pesquisa sobre o pensamento de Antonio Gramsci. Tendo tomado contato com as concepções gramscianas ainda no Rio de Janeiro, em 1974, Edmundo contribuiu enormemente para o progresso dos estudos sobre Gramsci no Brasil, destacando de modo precursor os escritos de juventude do marxista sardo, e realizando uma reflexão profícua em torno da questão da hegemonia.

* Professor aposentado do Instituto de Filosofia e Ciências Humanas (IFCH) da Universidade Estadual de Campinas (UNICAMP), o Prof. Dr. Edmundo Fernandes Dias tem sido um dos importantes intelectuais na investigação e disseminação da teoria social crítica e, especialmente, do pensamento social de Antonio Gramsci. A entrevista foi realizada, virtualmente, pela Profa. Dra. Monica de Jesus Cesar, integrante da Equipe Editorial da Revista Em Pauta e docente adjunta da Faculdade de Serviço Social da Universidade do Estado do Rio de Janeiro (FSS/UERJ), em julho de 2012. 


\section{ReVistg all pguttd}

A ideia de entrevistar o Professor Edmundo Dias surgiu a partir do próprio tema desse número da Revista - Teoria Social e Serviço Social -, considerando a sua admirável interpretação das formulações de Antonio Gramsci, cujo pensamento

se tornou uma referência cada vez mais frequente no Serviço Social e uma importante influência nas Ciências Sociais brasileiras. A difusão e valorização dos escritos do jovem Gramsci pelo Prof. Edmundo Dias Ihe possibilitou construir

uma leitura que evidencia a questão da revolução socialista como sendo a principal reflexão e preocupação do marxista sardo. O Professor Edmundo Dias, portanto, tem a nos oferecer não só uma formulação consistente sobre a obra de Antonio Gramsci como também uma interpretação alternativa que subleva o caráter orgânico de seu pensamento. Convidamos o leitor a conhecer as ideias fecundas e instigantes de Edmundo Fernandes Dias sobre os dilemas que a teoria social crítica enfrenta, atualmente, para explicar diversos fenômenos contemporâneos e sobre sua interlocução com o Serviço Social.

Em Pauta: Considerando sua história de vida, como iniciou o seu interesse pela política e pelas Ciências Sociais?

Prof. Dr. Edmundo Dias: Inicialmente pensei em trabalhar na área de História, mas as Ciências Sociais me pareciam mais complexas (incluindo aí a própria História). Mas foi a contrarrevolução preventiva de 64 promovida pelo grande capital com a cobertura das forças burguesas que me fez trabalhar articuladamente política e ciências sociais.

EP: De que forma a teoria social marxista alimentou seu trabalho acadêmico e sua trajetória política?

ED: Foi absoluta essa conexão. Penso que sem o marxismo nossa reflexão sobre a esfinge capitalista - como dizia Marx, a forma de extração do mais-valor - é o que nos permite pensar rigorosamente o movimento e o antagonismo das classes. Não poderia fazer o que fiz e faço sem a contribuição do marxismo. Isso seria impossível.

EP: Hoje a universidade está cindida entre a possibilidade de produção de um conhecimento crítico e a exigência de uma formação adequada ao mundo da produção, que atenda aos requisitos do mercado de trabalho, ao mesmo tempo em que é atravessada pelas exigências de um "produtivismo acadêmico a qualquer custo". Existe alternativa para essa cisão existente na universidade?

ED: Há aqui uma contradição. Se a universidade - ou melhor, a CAPES - exige uma produção a qualquer custo (produtivismo), como formar para o mercado com qualidade? É possível, no entanto, que o profissional produza com a correção e a dignidade? É. Aqui o problema é saber a quem atender: ao povo (conjunto das classes subalternas), ao mercado ou ao Estado. Isso depende do projeto político do pesquisador/docente.

EP: Qual a sua visão sobre a emergência das correntes de pensamento ditas "pósmodernas"? 


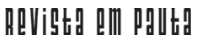

ED: Trata-se uma forma sofisticada de dominação. Por ela busca-se negar qualquer visão de totalidade.

EP: Numa entrevista concedida a Leandro Konder em 1969, Lukács afirmou que o irracionalismo e o racionalismo formal podem ser rapidamente combinados, conforme as necessidades do combate movido pela ideologia burguesa contra a razão dialética. Em sua opinião, a crítica às meganarrativas feita pela epistemologia pósmoderna expressa uma tentativa de desqualificação do racionalismo dialético?

ED: Considero que a resposta à questão anterior nos ajuda a responder essa pergunta. Contrariamente ao que muitos afirmam essas duas visões são formas de racionalidade de classe e, obviamente, combatem a prática proletária.

EP: Nas teorias pós-modernas há um consenso de que todo o estilo industrial de vida, legado da Revolução Industrial, foi solapado com o ingresso de uma nova era "pós-industrial", em que ganha relevo a informação e a comunicação. Uma era "pós-fordista", em que proliferam as pequenas empresas e renasce o trabalho artesanal. Uma era "pós-moderna" cuja ênfase reside nos elementos reveladores da descontinuidade, da ruptura e da diversidade. Os termos pós-industrial, pós-fordismo, pós-modernismo são empregados dentro do mesmo campo semântico. O prefixo "pós" virou uma panaceia?

ED: Não virou uma panaceia, mas um poderoso instrumento de guerra. Trata-se da desqualificação do trabalho vivo. A força de trabalho é pensada como manifestação da tecnologia. Deixa-se de pensar o sujeito revolucionário. Da luta de classes passase à harmonia. A cidadania é decisiva para afirmar a derrota das forças do trabalho.

EP: A reestruturação capitalista, a globalização econômica, o neoliberalismo e todas as transformações que se generalizam no âmbito da chamada "pós-modernidade" podem ser pensadas a partir de Marx? O que há de atual nesse pensador alemão do século XIX que possa ser útil aos grandes dilemas do século XXI?

ED: Penso que devemos responder positivamente. O arsenal categorial de Marx é cada vez mais atual.

EP: Quais os principais desafios teóricos e políticos que o marxismo enfrenta no mundo contemporâneo? Se perguntarmos para onde vai a tradição marxista, seria possível afirmar que seu futuro filosófico está assegurado?

ED: Considero o determinismo e o sectarismo como os principais problemas. Decifrar a esfinge capitalista permitirá avançar na reflexão da sociedade comunista não como um modelo pronto e acabado, mas como construção de uma subjetividade para além da ordem do capital.

EP:No Serviço Social, a produção acadêmica e o projeto profissional são influenciados pela tradição marxista. Contudo não é rara a crítica à "ortodoxia marxista" e às supostas lacunas existentes entre teoria e prática. Em sua opinião, a teoria marxiana é uma teoria capaz de superar o velho chavão de que "na prática a teoria é outra"? 


\section{ReVista dII paltid}

ED: Esse chavão implica um sentimento de adaptação à ordem. Obviamente ele é de uma falsidade enorme. A teoria marxista não tem sido desmentida por uma prática desqualificada. O capitalismo venceu? Seguramente não, embora no plano ideológico isso ocorrer. Mas a miséria não foi eliminada.

EP: Há uma grande influência do pensamento Gramsciano no Serviço Social, principalmente a questão da constituição da hegemonia e o papel do intelectual orgânico nesse processo. De que modo as concepções de Gramsci podem contribuir para um trabalho social que tem a transformação da sociedade como o seu horizonte ético-político?

ED: Podem fazê-lo na medida em que permitem compreender a realidade como articulação contraditória de racionalidades de classe. Exemplo? Estado e Terceiro Setor não são formas democráticas, mas, pelo contrário, implicam a captura da subjetividade antagonista. Desarmam o conjunto das classes subalternas. Mecanismo, Sectarismo são instrumentos que reforçam a opressão capitalista. Gramsci nos oferece instrumentos para fazer esse combate.

EP: E, finalmente, considerando sua interlocução com o Serviço Social no Brasil, bem como o tema desse número da revista que é o da articulação entre Teoria Social e Serviço Social, em sua opinião, quais contribuições da tradição marxista, em especial do pensamento gramsciano, são fundamentais para essa profissão na atualidade?

ED: Fundamentalmente a análise das conjunturas, a análise das ideologias, e considero essencial a análise do modo de vida dos oprimidos. 